\title{
Extração, secagem e torrefação da amêndoa do pequi (Caryocar brasiliense Camb.)
}

\author{
Extration, drying, and toasting of the pequi almond (Caryocar brasiliense Camb.)
}

\author{
Ana Maria da Silva RABÊLO ${ }^{1}$, Maria Célia Lopes TORRES ${ }^{1 \star}$, Robson Maia GERALDINE${ }^{1}$, Miriam Fontes Araujo SILVEIRA ${ }^{1}$
}

\begin{abstract}
Resumo
O pequi (Caryocar brasiliense Camb.) possui em seu interior amêndoa comestível pouco explorada. Objetivou-se avaliar o processo de extração, secagem e torrefação da amêndoa do pequi. Foram utilizadas sementes de pequi fornecidas pela Associação de Beneficiamento de Frutos do Cerrado, localizada na cidade de Damianópolis-GO. Para a extração da amêndoa, foi adaptado equipamento tipo guilhotina, com a finalidade de cortar a semente ao meio. O equipamento é composto por uma lâmina fixa em um suporte de madeira, recoberto com placa de Policloreto de Vinila (PVC) e apresentou desempenho satisfatório. Para a secagem das amêndoas, sugeriu-se o binômio tempo/temperatura de $70{ }^{\circ} \mathrm{C}$ por 60 minutos, pois conferiu ao produto atividade de água em torno de 0,60 em menor tempo secagem. As amêndoas torradas a $130{ }^{\circ} \mathrm{C}$ durante 15 e 30 minutos apresentaram melhores características sensoriais, não diferindo significativamente entre si $(\mathrm{p}>0,05)$ pelo Teste de Friedman. No tempo de 30 minutos, observaram-se tendências de melhores características sensoriais, como cor e crocância, no produto final.
\end{abstract}

Palavras-chave: amêndoa de pequi; extração; secagem; torrefação; análise sensorial; atividade de água.

\begin{abstract}
The Pequi (caryocar brasiliense Camb.) edible almond seed is little used. The aim of this study is to evaluate almond seeds of pequi supplied by the "Associação de Beneficiamento de Frutos do Cerrado" (Cerrado fruit supply association), located in the city of Damianópolis-GO. For the extration of the almond, a guillotine like equipment was used with the purpose of cutting the seed in half. The equipment was composed of a fixed blade placed in a wooden support, recovered with Polyvinyl chloride (PVC), and it presented satisfactory performance. For the almonds drying, the temperature of $70^{\circ} \mathrm{C}$ for 60 minutes was suggested since it allowed water activity of around 0,60 in shorter drying time. The almonds roasted at $130^{\circ} \mathrm{C}$ for 15 and 30 minutes presented better sensorial characteristics, and proved not significantly different among themselves $(P>0,05)$ in the Friedman Test. In the time of 30 minutes, trends of better sensorial characteristics such as color and crunchiness of the final product were observed
\end{abstract}

Keywords: pequi almond, extraction, drying, toasting, sensorial analysis, activity of water.

\section{Introdução}

O pequi (Caryocar brasiliense Camb.) é uma planta arbórea que engloba cerca de 20 espécies, a maioria de porte alto, compondo a vegetação da floresta amazônica e estendendo seu habitat natural aos países limítrofes, principalmente, Peru, Suriname e Guianas. No Brasil, o pequi distribui-se desde o Pará e o Amazonas, sua área de maior ocorrência, aos Estados do Nordeste e, ainda, aos Estados do Mato Grosso do Sul, Goiás, Minas Gerais, São Paulo e norte do Paraná. É uma planta típica de cerrado e das caatingas (FACIOLI, 1996).

Dentre as 19 espécies pertencentes à família Caryocaraceae, pode-se destacar a Cariocar brasiliensis, cujo nome vulgar é pequizeiro, por ser a planta produtora do pequi, fruto de secular aproveitamento. O nome do fruto origina-se do tupi "pyqui", no qual py significa pele, e qui, espinho, referindo-se aos espinhos do endocarpo do fruto (parte dura do caroço) (HERINGER, 1969; ALMEIDA; SILVA, 1994).
O pequi possui em seu interior amêndoa comestível pouco explorada. A polpa e a "amêndoa" nele encontradas são ricas em riboflavina, tiamina, provitamina A e em óleos que lhe confere grande valor nutritivo. A "castanha" é utilizada na fabricação de paçoca e óleo branco (POZO, 1997).

As empresas processadoras de produtos que utilizam a polpa, após sua retirada, acabam se desfazendo do restante. Isto tem contribuído para um menor valor agregado ao pequi, além de constituir subproduto descartado ao meio ambiente. Assim, faz-se necessário desenvolver métodos que permitam o aproveitamento da amêndoa como mais uma fonte alimentar, por possuir ótimo sabor e valor nutritivo (FACIOLI, 1996).

Por ser um fruto que obedece a safra e sendo sua amêndoa pouco explorada, objetivou-se avaliar o processo de extração, secagem e torrefação da amêndoa do pequi.

Recebido para publicação em 27/6/2007

Aceito para publicação em 27/5/2008 (002638)

1 Setor de Engenharia de Alimentos, Escola de Agronomia e Engenharia de Alimentos, Universidade Federal de Goiás - UFG, CEP 74001-970, Goiânia - GO, Brasil,

E-mail: celialopes@agro.ufg.br

${ }^{*}$ A quem a correspondência deve ser enviada 


\section{Material e métodos}

Foram utilizadas sementes de pequi fornecidas pela Associação de Beneficiamento de Frutos do Cerrado, localizada na cidade de Damianópolis-Go. Os frutos foram colhidos em um raio máximo de $30 \mathrm{~km}$ da cidade, nos meses de Dezembro/2005 a Janeiro/2006.

Após serem despolpadas manualmente, as sementes de pequi foram colocadas sobre lona plástica, onde permaneceram secando ao sol durante 7 dias. As sementes foram, então, transportadas até o Setor de Engenharia de Alimentos da Escola de Agronomia e Engenharia de Alimentos - UFG.

\subsection{Extração da amêndoa}

As sementes foram lavadas em água corrente e agitadas em tanquinho rotativo (marca Colormaq) por 5 minutos. Novamente foram enxaguadas e imersas em solução de 200 ppm de cloro ativo por 5 minutos, utilizando-se hipoclorito de sódio.

Em seguidas, as sementes foram dispostas em bandejas e levadas para uma estufa, com circulação forçada de ar, a $70{ }^{\circ} \mathrm{C}$ durante 4 horas para retirada de umidade.

Para a extração da amêndoa, foi adaptado um equipamento tipo guilhotina, com a finalidade de cortar a semente ao meio. O equipamento, composto por uma lâmina fixa (foice) em um suporte de madeira, recoberto com placa de policloreto de vinila (PVC), foi desenvolvido durante o experimento para facilitar o processo de extração (Figura 1).

Após o corte, as amêndoas foram lavadas em água corrente para retirada dos espinhos, sanificadas em solução clorada a 200 ppm por 5 minutos e levadas à centrífuga de vegetais (marca Trident), para secagem superficial por 5 minutos.

\subsection{Determinação da curva de secagem}

A curva de secagem foi obtida mediante determinação de umidade inicial e final da amêndoa, em estufa de secagem com circulação forçada (marca Marconi, mod. MA 035) de ar quente, sob condições de temperatura controlada a 60 e $70{ }^{\circ} \mathrm{C}$. O ponto final para a determinação do tempo da secagem foi a redução da aw em torno de 0,6 (SOUZA et al., 1986).

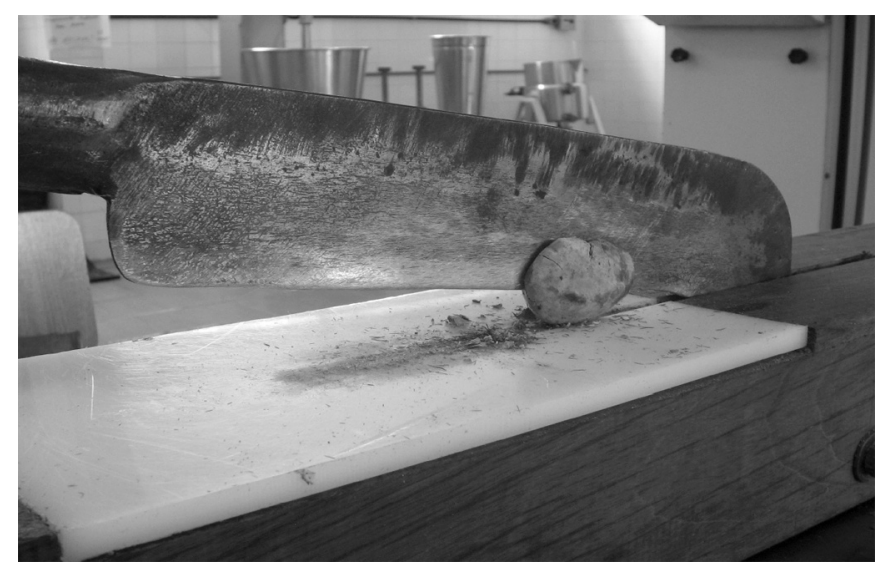

Figura 1. Guilhotina adaptada para extração da amêndoa.
Foi colocado em torno de $1 \mathrm{~kg}$ de amêndoas em cada bandeja, distribuídas de forma homogênea. Para determinações de umidade e aw, foram coletadas amostras a cada 10 minutos.

$\mathrm{A}$ atividade de água $(\mathrm{Aw})$ foi determinada em analisador AQUALAB, devidamente calibrado. As análises para determinação da umidade $\left(105^{\circ} \mathrm{C}\right)$ até atingir peso constante foram realizadas segundo AOAC (1997). Foram realizadas 3 repetições com 2 réplicas.

\subsection{Torrefação e avaliação sensorial}

As amostras foram secas no tempo e temperatura escolhidos de acordo com as curvas de secagem. A seguir foram torradas a $130{ }^{\circ} \mathrm{C}$, em estufa com circulação forçada de ar, em diferentes tempos (15, 30 e 45 minutos) e submetidas à avaliação sensorial, utilizando-se o teste de preferência (ordenação) segundo Dutcosky (1996), para definição do melhor tempo de torrefação. A análise foi realizada com provadores não treinados em cabines individuais. A amostra seca (sem torrefação) foi oferecida aos provadores entre as amostras torradas para a escolha da preferida.

\subsection{Análise estatística}

Os dados obtidos foram submetidos à análise de regressão e Teste de Friedman. As análises foram realizadas com o auxílio do programa Statistica versão 6.0 (StatSoft).

\section{Resultados e discussão}

\subsection{Extração da amêndoa}

O equipamento adaptado permitiu fácil e rápido corte da semente no sentido longitudinal para extração da amêndoa (Figura 1). Não foi possível a retirada da amêndoa inteira devido ao formato e espinhos presentes na semente. Foi necessária a utilização de facas para retirar algumas amêndoas que ainda ficaram aderidas às sementes e luvas de látex para proteção das mãos dos manipuladores.

A lavagem em água corrente dentro de cestos foi eficiente para eliminar resíduos de espinhos das amêndoas. A secagem superficial, obtida após centrifugação em tanque rotativo, foi também eficiente e não provocou danos mecânicos.

\subsection{Determinação da curva de secagem das amêndoas}

As amostras apresentaram umidade inicial em torno de 14\% (Figura 2). Nos primeiros 20 minutos de secagem, ocorreu decréscimo acentuado na umidade do produto. Após 40 minutos, a umidade das amêndoas foi reduzida para 10,2 e 8,2\%, quando submetidas às temperaturas de 60 e $70^{\circ} \mathrm{C}$, respectivamente. A partir deste tempo, para ambas as temperaturas, observou-se a tendência de estabilização da umidade. O processo de secagem apresentado neste trabalho mostrou-se mais eficiente do que o utilizado por Silva (2005), que gastou de três a quatro semanas para reduzir a umidade de noz macadâmia para $10 \%$, utilizando pré-secagem no campo, por convecção natural de ar à sombra. 


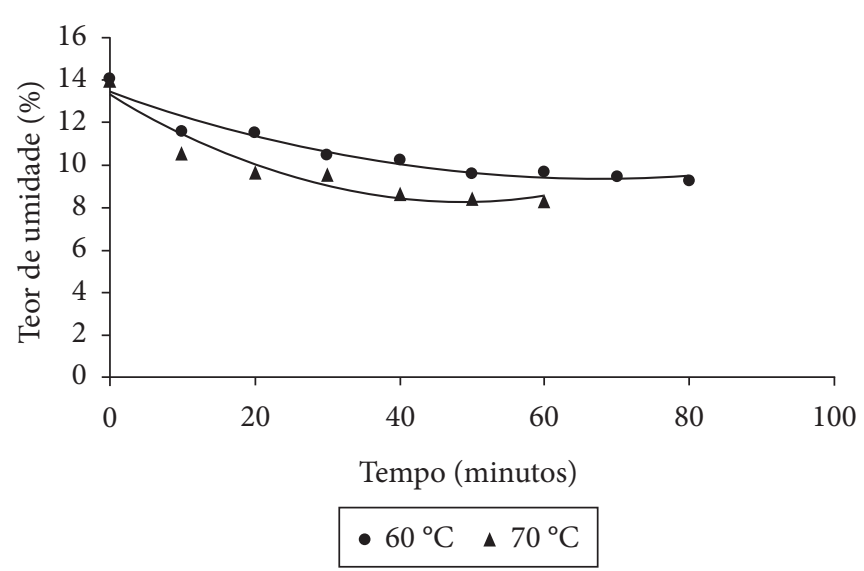

Figura 2. Teor de umidade da amêndoa de pequi a temperaturas de 60 e $70^{\circ} \mathrm{C}$.

A atividade de água inicial da amostra foi de 0,93 (Figura 3) e apresentou comportamento semelhante ao da umidade; nos primeiros 20 minutos de secagem houve um decréscimo acentuado da atividade de água das amostras, para as temperaturas estudadas, alcançando valores próximos a 0,80 . As amostras submetidas a $60^{\circ} \mathrm{C}$ apresentaram menor redução na atividade de água, enquanto que a $70{ }^{\circ} \mathrm{C}$, após 60 minutos de secagem, foram observados valores em torno de 0,60.

Pela análise dos dados, sugere-se o binômio tempo/temperatura de secagem das amêndoas de $70{ }^{\circ} \mathrm{C}$ por 60 minutos, pois conferiu ao produto atividade de água em torno de $0,60 \mathrm{em}$ menor tempo secagem. Souza et al. (1986), também, utilizaram temperatura de $70^{\circ} \mathrm{C}$ na secagem de farinha de amêndoa de castanha do Brasil (Bertholletia excelsa), reduzindo sua umidade para 2,3\% em três horas.

\subsection{Torrefação e avaliação sensorial}

As amostras secas $\left(70{ }^{\circ} \mathrm{C} / 60 \mathrm{~min}\right)$ e torradas a $130^{\circ} \mathrm{C}$ por 15,30 e 45 minutos, apresentaram umidade final de 4,27 , 3,86 e $3,60 \%$ e atividade de água de $0,35,0,29$ e 0,19 , respectivamente.

Não houve diferença significativa ( $\mathrm{p}>0,05)$, com relação à preferência, entre as amostras torradas durante 15 e 30 minutos pelo Teste de Friedman. As amêndoas apenas secas e as torradas por 45 minutos também não diferiram estatisticamente entre si $(\mathrm{p}>0,05)$ em relação à preferência, sendo menos preferidas pelos provadores (Figura 4). Apesar das amostras torradas por $15 \mathrm{e}$ 30 minutos não apresentarem diferença significativa em relação à preferência, sugere-se o tempo de torrefação de 30 minutos, pois foram observadas tendências de melhores características sensoriais de cor e crocância, no produto final.

\section{Conclusões}

O processamento tecnológico para obtenção da amêndoa torrada foi eficiente e fácil de ser utilizado por pequenas indústrias beneficiadoras de pequi, bem como cooperativas.

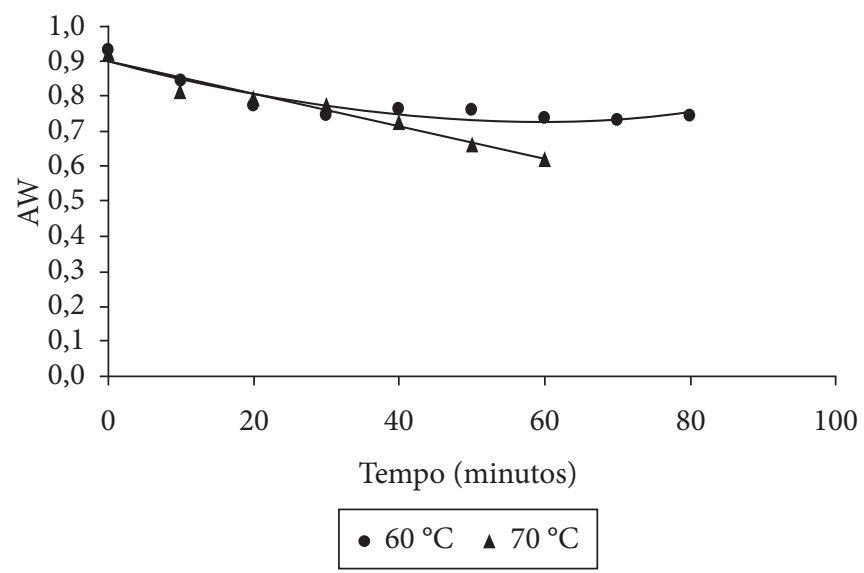

Figura 3. Aw da amêndoa de pequi a temperatura de 60 e $70^{\circ} \mathrm{C}$.

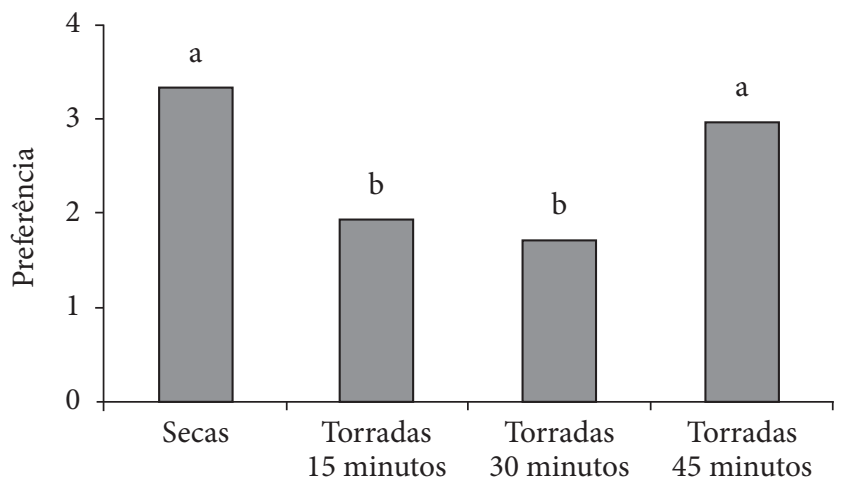

Figura 4. Preferência dos provadores pelas amostras de amêndoas secas e torradas. Barras com a mesma letra não diferem estatisticamente entre si (Teste de Friedman). Amostras com menor valor de soma de ordens foram mais preferidas.

O binômio tempo/temperatura para secagem das amêndoas de $70^{\circ} \mathrm{C}$ por 60 minutos conferiu ao produto atividade de água em torno de 0,60 em menor tempo de secagem.

As amêndoas torradas a $130{ }^{\circ} \mathrm{C}$ durante 15 e 30 minutos apresentaram melhores características sensoriais, não diferindo significativamente entre si $(\mathrm{p}>0,05)$. Contudo, no tempo de 30 minutos, observou-se que as características sensoriais de cor e crocância, no produto final, foram ligeiramente superiores.

\section{Agradecimentos}

À CAPES pelo apoio financeiro.

\section{Referências bibliográficas}

ALMEIDA, S. P.; SILVA, J. A. Pequi e Buriti. Importância alimentar para a população dos cerrados. Platina: Embrapa - CPAC, 1994. $38 \mathrm{p}$.

AOAC. Official Methods of Analysis of Association of Official Analytical Chemist's. Arlington: Ed. HELRICH, 1997. 1850 p.

DUTCOSKY, S. D. Análise sensorial de alimentos. Curitiba: Champagnat, 1996. $123 \mathrm{p}$. 
FACIOLI, N. L. Modificação via enzimática da composição triglicerídica do óleo de Piqui (Caryocar brasiliense camb.). Campinas, 1996, 120 p. Dissertação - (Mestrado em Ciência e Tecnologia de Alimentos), Faculdade de Engenharia de Alimentos, Universidade Estadual de Campinas - UNICAMP.

HERINGER, E. P. O pequizeiro (Caryocar brasiliensis Camb.). Brasil Florestal, v. 1, n. 2, p. 28-31, 1969.

POZO, O. V. C. O pequi (Caryocar brasiliense Camb.): uma alternativa para o desenvolvimento sustentável do cerrado no norte de Minas Gerais. Lavras, 1997. 97 p. Dissertação - (Mestrado em Administração Rural), Faculdade de Agronomia, Universidade Federal de Lavras - UFLA.

SILVA, F. A. Estudo da Aplicação de Energia de Microondas na Secagem da Noz Macadâmia (Macadamia integrifólia Maiden \& Bech). Campinas, 2005, 151 p. Tese (Doutorado em Engenharia de Alimentos), Faculdade de Engenharia de Alimentos, Universidade Estadual de Campinas - UNICAMP.

SOUZA, M. L. et al. Estudo do processamento e estabilidade da farinha de amêndoa da castanha-do-brasil (Bertholletia excelsa H.B.K.). Ciência Agronômica, v. 7, n. 1. p. 35-42, 1986.

STATSOFT. Statística versão 6.0, Copyght 1984-2000 by StatSoft, Inc. 